\title{
The Internet Dilemma: An Exploratory Study of Luxury Firms' Usage of Internet-Based Technologies
}

\begin{abstract}
Surprisingly, there exists a paucity of research examining the adoption of Internet-based technologies by luxury firms. This represents a major shortcoming in our understanding of how luxury firms maintain the image of their brand, sustain a personal link with customers, and retain an aura of exclusivity as they seek to provide their products and services to increasingly technologically-astute customers. Using content analysis, we present the findings of a qualitative investigation of 92 luxury firm websites across the categories of automobiles, fashion, jewelry, watches, and yachts. Study findings indicate that there are noticeable differences in website characteristics and functionality across sectors. Implications of the results are discussed, noting that decisions about using the Internet for branding and selling, one-way and two-way communications, as well as operational and innovative features, are driven by the characteristics of the products being offered. Avenues for future research are also offered.
\end{abstract}

Keywords: Luxury firm, website, digital, adoption, Internet, qualitative research, content analysis, $8 \mathrm{C}$ framework

Preprint version of:

Baker, J., Ashill, N., Amer, N., and Diab, E. "The Internet Dilemma: An Exploratory Study of Luxury Firms' Usage of Internet-Based Technologies". Journal of Retailing and Consumer Services. Volume 41 (2018), pp. 37-47. https://doi.org/10.1016/j.jretconser.2017.11.007 


\section{Introduction}

The past two decades have seen myriads of firms incorporate IT into their marketing, retailing, and customer service. One segment of the global economy that has been slow to adopt and utilize IT, however, is the luxury industry (Bjørn-Andersen and Hansen, 2011; Okonkwo, 2009). Luxury is a large and growing industry, with global revenues of over $\$ 250$ billion in 2013 (D'Arpizio, 2013). While growth in many industries is being driven by e-commerce, $40-50 \%$ of luxury firms choose not to sell online (Berger, 2012; D'Arpizio, 2013). In an effort to explain the slow adoption and usage of IT by luxury firms, a controversy has evolved regarding whether luxury firms should use the Internet purely as a means to communicate or whether to also use it as a sales channel (Hennigs et al., 2012; Kapferer and Bastien, 2012; Okonkwo, 2009; Seringhaus, 2005). Firms from Rolls-Royce and Ferrari, to Louis Vuitton and Prada, to Tiffany and Cartier face the "Internet Dilemma" of how to maintain the image of their brand, sustain a personal link with customers, and retain an aura of exclusivity as they seek to provide their products and services to an increasingly technologically-astute customer base.

Against this backdrop, we explore whether and how different luxury sectors have embraced Internet-based technologies. We focus specifically on the firm website. Given that luxury firms place a high priority on the relationships that they form with their customers (Tynan et al., 2010), customer-facing technology such as the firm's website should be a key indicator of the firm's stance towards using the Internet as a branding and selling tool. Furthermore, web sites have taken on a prominent role in online communication and as a distribution channel (Keller, 2010). By examining and analyzing the elements used - or not used - on a luxury firm's website, we seek to uncover the characteristics of luxury firms, their products, and their strategies that lead them to make specific choices about the adoption of Internet-based technologies. The research questions 
guiding our efforts in this paper are: "What are the characteristics of luxury firms' websites?" and "How do luxury firms differ in their use of website characteristics across different sectors?"

Our primary intended contribution is an explanation of the systematic differences in website characteristics across different industry sectors. After first developing a descriptive account of website characteristics utilized by various luxury sectors, we then examine how product attributes, as well as existing literature and theory, provide insight into how customers want to interact with a luxury firm, before finally developing prescriptive suggestions for practitioners. We also present conceptual and theoretical insights into how and why firms use particular website features and characteristics.

Our paper is organized as follows. First, we review current literature on online marketing and e-commerce in the luxury industry, highlighting the debate in scholarly research about the role of the Internet. We then report a qualitative study of 92 global luxury firm websites across five different luxury sectors. We utilize one of the most-recognized conceptual frameworks for evaluating firm websites, the 8C framework (Bjørn-Andersen and Hansen, 2011; Lee and Benbasat, 2004; Rayport and Jaworski, 2001; Sabouri and Jalali, 2009; Yang et al., 2008). As we evaluate luxury firm websites, we are able to identify distinct patterns in the usage of various web interface elements across different industry sectors. After reporting our results, we discuss the theoretical and practical implications of these patterns for luxury firms as they consider their emarketing and e-commerce strategies.

\section{Literature Review}

\subsection{Luxury Firms}

Many different definitions of luxury exist (De Barnier et al., 2012; Kapferer and Bastien, 2012), but they share a common core of six criteria: (a) a very qualitative hedonistic experience, 
(b) offered at a price that far exceeds what the functional value would command, (c) tied to heritage, unique know-how and culture, (d) available in restricted and controlled distribution, (e) offered with personalized accompanying services and (f) representing a social marker, where the purchaser feels special with a sense of privilege (Kapferer and Bastien, 2012). By their very nature, luxury brands can be characterized as conspicuous, unique, social, emotional and of very high quality. Ultimately, the concept of luxury is built on consumers' perceptions, and is determined by personal and interpersonal motives and is strongly influenced by culture (Vigneron and Johnson, 2004).

The symbolic value of a luxury brand, acquired through quality, creativity and status, is central to its success. In luxury, brand image is identified as a salient resource to gain competitive advantage (Kapferer and Bastien, 2012). Brand image is acknowledged to be a key component of brand equity which is defined as the "differential effect that brand knowledge has on consumer response to the marketing of that brand" (Keller, 2008). Not surprisingly, understanding those factors that increase brand equity is critical to brand management. There is an abundance of research that has examined the actions that organizations can take with customers to build brand equity (Yoo et al., 2000), but a lack of research on those actions taken within the organization.

Given the ultimate goal of building brand equity, luxury firms have considered ways in which IT can be used. Extant research on the use of IT within luxury firms can be generally grouped around several themes: consumer and purchase behavior in an online environment (Brun et al., 2013), website design (Kluge et al., 2013), the role of web and mobile technologies (Mahyari, 2013), the role of social media when engaging with luxury firms (Kim and Ko, 2012; Riley and Lacroix, 2003) and the role of the internet in communications strategy (Geerts, 2013). We observe that each of these themes touch on the importance of the Internet to luxury firms. We also observe, 
however, that a systematic study of how the Internet is used in these firms has not yet been undertaken. It is this gap in existing research that we seek to address.

\subsection{Luxury Firms and the Internet Dilemma}

While online digital marketing has become decidedly mainstream, luxury firms have been slow to embrace the Internet's potential. Part of the reason for this reluctance is what has been termed "the Internet Dilemma." The Internet Dilemma is a term coined to describe the challenge luxury firms face as they seek to maintain the image of their brand, sustain a personal link with customers, and retain an aura of exclusivity as they simultaneously seek to provide their products and services to increasingly technologically-astute customers (Kapferer and Bastien, 2012).

Part of the dilemma arises from divergent opinions about the purpose of a luxury firm's website. It is generally acknowledged that a firm's website acts as a branding tool where information is exchanged between buyers and sellers (Kiang et al., 2000). In branding and communication strategies, the Internet is a complementary tool that is used to inform, remind, and persuade (Nyeck, 2004). A firm's website therefore helps to establish links between consumers and brands. A dilemma arises, however, when one also acknowledges that the firm's website also has the ability to serve as a transaction medium (Kim and Stoel, 2004). Thus, one of the key considerations for luxury firms as they address the Internet Dilemma is whether they will use the Internet for branding or selling.

Some contend that the Internet strategy of a luxury firm should be limited to communication (Kapferer and Bastien, 2012). Selling - rather than simply communicating online - potentially undermines the feelings of exclusivity attached to the brand, significantly reduces the efforts of consumers to access luxury (efforts that are a core part of the creation of desire in luxury), and diminishes the personalization of the transaction (Hennigs et al., 2012). It has even been stated 
that if a luxury product is for sale on the Internet, and thus for sale broadly and commonly to the masses, it can no longer be considered a luxury product (Kapferer and Bastien, 2012). Researchers taking this perspective argue that the inability of the Internet to provide a rarefied, distinctive, multisensory shopping experience outweighs the potential benefits of selling online and therefore recommend that luxury firms wait for more immersive Internet experiences in the future.

Others, however, recommend that luxury firms should not only communicate online, but should also engage in online retailing (Hennigs et al., 2012; Okonkwo, 2009). Because the Internet has become a source of information and purchase for affluent consumers, luxury firms cannot afford to miss the opportunity to make use of this sales channel. When luxury firms can use the Internet to leverage movement, music, texture, space, and community to successfully, artfully, and compellingly communicate brand identity online, a premium and even luxurious online experience can be created, thus aligning the Internet experience with the overall identity of the luxury brand (Okonkwo, 2010). As long as a premium experience can be created online, and as long as the price premium associated with luxury products can be maintained in the virtual world via limited distribution, the potential downside of the Internet being a public, non-exclusive marketspace of immediate buying and selling can be minimized (Hennigs et al., 2012; Okonkwo, 2009).

Indeed, there appears to be a general trend of migration from the traditionalist approach to one that embraces many of the capabilities of the Internet. Early studies assessing B2C luxury websites in the fashion sector showed that luxury fashion firms generally did not have interactive, entertaining or engaging websites, and therefore did not meet consumer expectations (Dall'Olmo Riley and Lacroix, 2003; Seringhaus, 2005; Siddiqui et al., 2003). Luxury firms are, over time, however, moving to incorporate transactional capabilities on their websites so that they can sell online. Indeed, a longitudinal study of 15 luxury fashion brands over the time period from 2006 
to 2012 identified increasing rates of adoption and usage of e-commerce (Hansen and BjornAndersen, 2013). In sum, while a growing number of firms are opting to use the Internet for both branding and selling, the issue is far from settled.

Luxury firms also highly value ongoing relationships with their clients (Atwal and Williams, 2009) and have to consider whether they will use the capabilities of the Internet to engage in oneway or two-way communication. One-way communication is defined as the transmission of a firm's messages to consumers (but not in the other direction, from consumers to the firm). Twoway communication refers to the ability for reciprocal communication between firms and consumers, and also between consumers and other consumers (Liu and Shrum, 2002). Many luxury firms may be predisposed to one-way communication on the Internet, given their desire to maintain control of their image, and to preserve selectivity and rarity (Geerts and Veg-Sala, 2011). The Internet is generally understood to be a mass medium of communication, one that is neither selective nor exclusive. Two-way communication offers the potential to enhance relationships with customers, but the challenge for luxury firms is to engage in this communication only with a selected portion of the population (Vigneron and Johnson, 2004).

There is evidence to suggest that luxury firms want to maintain this focus on consumer relationships and ongoing interaction with consumers online (Bjørn-Andersen and Hansen, 2011; Kim and Ko, 2012; Okonkwo, 2009; Phan et al., 2011). Luxury consumers are no longer just looking for one-way communication from brands; rather, consumers desire two-way interaction that comes in the form of dialogue, exchanges, sharing, entertainment, and engagement (Okonkwo, 2009). Luxury consumers want a website that can offer social interaction, two-way communication and a personalized relationship (Bjørn-Andersen and Hansen, 2011; Kim and Ko, 2012). The benefits of Web 2.0 in creating user-generated content are widely acknowledged 
(Constantinides and Fountain, 2008; Wiedmann and Hennigs, 2013), suggesting that the Internet strategies of luxury firms allow for two-way interaction with consumers. A study of luxury wristwatch manufacturers found that communication and interactivity tools were used on a large scale (Barbosa et al., 2013). Thus, despite the reluctance of many luxury brands to move many of their customer-facing activities online, there appears to be growing consensus that luxury brands find value in using the Internet and social media platforms to achieve their strategic goals (Kluge and Fassnacht, 2015). Thus, a second consideration for luxury firms is whether they will use the capabilities of the Internet to engage in one-way or two-way communication.

There is also variation across firms and sectors as they consider where and how to utilize Internet capabilities across their value chain. Luxury firms must decide if they will use the Internet for simply for operations, or also for innovation. Some firms are using technology strictly to improve internal business processes, while others are taking a more pioneering approach. For instance, luxury fashion firms thrive on combining emotion, image, and perception (Atwal and Williams, 2009; Seringhaus, 2005). The challenge firms face in the online environment is how to convey these characteristics and create multi-sensory experiences using Internet technologies (Bjørn-Andersen and Hansen, 2011). Delivering a unique multisensory experience through sensorial stimulation of the customer's sight, taste, hearing, smell, and touch, has been described as being at the very heart of a luxury strategy (Okonkwo, 2009). Emotional appeal, style, and aesthetically appealing website design are likely to be more relevant than effectively communicating quality or technical performance specifications of the product (Berthon et al., 2009; Caniato et al., 2011; Caniato et al., 2009). Innovation that elevates the sensorial online experience is thus an important consideration for luxury fashion firms. 
In another example, websites selling fashion-related products also benefit from higher levels of social presence (Coursaris et al., 2006; Hassanein and Head, 2005), echoing the importance of interactivity in media richness (Daft and Lengel, 1986). Consumers experience a high degree of social presence when they experience others as psychologically present (Fulk et al., 1987). In a web environment, instilling social presence is accompanied by providing a means of actual interaction with other humans, often via innovative online features such as virtual communities, message boards, audio and video material, and rich text and picture content such as 3D and $360^{\circ}$ view. Such innovative technological features can enhance the engagement of customers and improve firms' communication with them (Okonkwo, 2009).

In still another example, innovation in website features can facilitate product customization and website personalization (Geerts, 2013; Hansen and Bjorn-Andersen, 2013). Customers may expect a degree of product customization, which is widely-available on websites for mass-market products. However, the luxury brand may resist such expectations in order to maintain full creative and artistic control over their products. In sum, an additional consideration for firms is whether they will use the Internet simply for operations, or also for innovation.

\subsection{Summary}

Ultimately, luxury firms have addressed the Internet dilemma in various ways. Some are cautious and staunchly traditional, using the Internet exclusively for branding, one-way communication to customers, and operational tasks. Others are at the vanguard of Internet usage also engaging in online e-commerce sales, facilitating two-way communication with customers, and seeking innovative uses of the Internet to market, advertise, and even customize their products (Hansen and Bjorn-Andersen, 2013). 
While research has been conducted on the use of the Internet by luxury firms, we observe that this extant work is limited in two ways. First, it examines only certain specific sectors rather than a broad spectrum of luxury firms. Fashion is by far the most common (Dall'Olmo Riley and Lacroix, 2003; Hansen and Bjorn-Andersen, 2013; Seringhaus, 2005; Siddiqui et al., 2003). The luxury market encompasses many additional sectors, however, ranging from automobiles to watches, to yachts and jewelry. These sectors vary significantly in terms of the products and their attributes (Caniato et al., 2011) and are understudied. Second, and following from our initial observation, extant research on luxury firms presents an unresolved dilemma - that of whether and how to use the Internet. There are clearly differences of opinion among researchers, and there are also clearly-observable differences in the approaches taken by various firms.

Against this backdrop of growing consensus that luxury firms should embrace the Internet and social media platforms, but amidst dissension on how to do so, we now present a descriptive study of the ways in which luxury firms are addressing the Internet Dilemma.

\section{Research Methodology}

\subsection{Sample}

In this research, our primary interest is understanding how luxury firms across diverse industry sectors utilize digital Internet-based technologies on their websites. We selected a sample of 92 luxury brands covering a broad range of luxury goods (autos, fashion, jewelry, watches, yachts). We relied on several well established luxury brand rankings/lists, including Agency Luxury (2014), Brand Networks (2011), Brandz (2012), Forbes (2013), Luxury Society (2014), World Luxury Association (2012) as well as Okonkwo's (2010) list of best practice luxury brand homepages to select luxury brand websites for the sample. An overview of the specific brands evaluated is provided in Table 1. 


\section{$\langle<<<\quad$ Insert Table 1 Here $\quad \gg>>>>$}

Our research utilized qualitative content analysis. Content analysis is a research methodology that involves making the content of messages manifest through identification of characteristics in as objective a way as possible (Bryman, 2008). The intention is to create a coding schema, or "membership categorization device", which encompasses a collection of categories and a set of rules on how to attribute data to these categories (David, 2005). The content analysis was based on an a priori classification system grounded in the 8C framework (Bjørn-Andersen and Hansen, 2011; Lee and Benbasat, 2004; Rayport and Jaworski, 2001; Sabouri and Jalali, 2009; Yang et al., 2008).

The 8C Framework emphasizes the specific role of website interface elements as a branding and sales channel between owners of a brand and its customers (Rayport and Jaworski, 2001). The framework adopts a strategic perspective towards evaluating websites that ensures consistency between a firm's web activities and marketing strategies. The framework includes a set of standardized design principles for e-commerce websites including (1) context, (2) content, (3) community, (4) customization, (5) communication, (6) connection, and (7) commerce, and (8) collaboration (Rayport and Jaworski, 2001; Yang et al., 2008).

The $8 \mathrm{C}$ framework has been applied in research on luxury firms (Hansen and Bjorn-Andersen, 2013). Prior research with luxury fashion firms reveals that firms must make at least three strategic choices (Hansen and Bjorn-Andersen, 2013). The first strategic choice relates to the purpose of the website, where the focus is either on branding or selling through the website. The second is the mode of interaction which can either be one-way where the message is distributed from the brand to customers, or two-way where individual consumers engage in interaction. And finally, the third strategic choice focuses on the level of interaction, where a brand faces the choice of 
whether to provide primarily operational features through the website or actively pursuing innovation on the website by providing features such as augmented reality, product customization, or online communities. The 8 categories differ in the extent to which each is primarily use to further branding or sales, whether the orientation of the website is primarily operational or innovative, and whether the communication is predominantly one-way or two-way. Definitions for each of the elements of the 8C Framework are included in Table 2.

\section{$\ll<<\quad$ Insert Table 2 Here $\quad \gg>>>$}

\subsection{Data Collection}

Observations of 92 luxury firm websites were initially conducted over a four-week period in 2015 by two members of the research team. Content analysis specifically focused on the textual and visual contents of each website. In a pilot test, two members of the research team, who had undergone a training session, independently viewed 10 websites. Responses utilizing the agreed upon coding system for the 8 categories (the 8Cs) and 29 sub-categories were compared (see Tables 2 and 3 for the $8 \mathrm{C}$ categories and their sub-categories, respectively). Results initially found an $8 \%$ inconsistency in the observations for the 10 websites, mainly due to subjective interpretations of the websites and degree of interaction with the site. All inconsistencies were subsequently explored and discussed by all four members of the research team and agreement was sought on the meaning of the assessment criterion.

In the main data collection phase, the same two researchers independently analyzed the content of web pages based upon the revised pre-set coding criteria. Where firms had multiple websites for multiple regions, the European English-language website was chosen.

The data collection consisted of logging codes. For example, a "1" indicated the feature was found on the website and " 0 " indicated the feature was not found. Total scores were generated for 
each of the 8 interface categories through which luxury brands communicate with their customers. To ensure the reliability of the analysis, the two coders conducted the coding separately. We calculated the percentage that the two coders agreed in their ratings as an index of coder agreement. For categorical data, this is expressed as the number of agreements in observations divided by the total number of observations. Coder agreement varied between $70.1 \%$ and $73.8 \%$ across the 5 luxury sectors. Cohen's Kappa (Cohen, 1968) for inter-rater reliability was also calculated to assess inter-rater reliability. Kappa is a function of the ratio of agreements to disagreements in relation to expected frequencies. It is considered a more robust measure than a simple percent agreement calculation because it accounts for chance (Krippendorf, 1980). The inter-rater reliability rate ranged from 0.76 to 0.85 across the five luxury sectors, exceeding the acceptable level of 0.70 and indicating good reliability (Landis and Koch, 1977). A group consensus procedure (involving all four researchers) was adopted to resolve inconsistencies and arrive at a final decision on whether a website characteristic was or was not present.

\section{Results}

Descriptive data for each of the 8 characteristics for each luxury sector are shown in Table 3. The $8 \mathrm{C}$ characteristic, Content, showed a consistent pattern across all five luxury sectors. The overwhelming majority of the examined 92 luxury brands implement one-way brand messages to customers using product descriptions, history and timeline, and corporate information. Four of the 5 luxury sectors also use their website to communicate information about marketing campaigns and special promotions. The exception is the yachting sector where adoption of this branding characteristic is low. The second characteristic, Community, also showed a consistent pattern across all five sectors. Our data suggests that very few luxury brands have developed both internal and external brand communities with most brands focusing on building communities using 
external sites such as Facebook, Instagram, and YouTube. Analysis of the third category, Communication, showed that the majority of brands across the 5 sectors offer the option of signing up for newsletters and display information about them and contact details. However, almost two thirds of the luxury brand websites examined (60 of the 92 websites) do not use videos as a communication tool to showcase interviews with designers, craftsmen, or celebrity ambassadors. No luxury brand website demonstrated collaboration related to design, co-creation, feedback or comments regarding product development. Instead, most luxury firms use social media channels as a platform to allow customers express their opinion and write their experience about the brand publicly.

Analysis of the fifth category, Connection, showed that the majority of luxury brands across all 5 luxury sectors do not link to third party selling sites (microsites) and place branded content on other sites (the phenomenon of syndication). In the fashion sector the use of electronic commerce and social media commerce is high. However, in watches, jewelry, and automobiles, its use is very low and non-existent in yachts. With regard to the website design context, flash, videos and 3D are used by most brands in the fashion sector to show their fashion show events. However, the adoption of animation, augmented reality and 360 degree view in this sector is significantly lower. A similar pattern for using flash and videos is also evident in the watches, jewelry, automobile, and yacht sectors. However, the use of augmented reality is very low suggesting that the adoption of these technologies has not yet reached luxury firms. The adoption rate for using 360 degree view is highest in the automobile sector. Finally, although product customization and personalization lie at the heart of luxury (Kapferer and Bastien, 2012), it is evident from the descriptive data that some luxury sectors are not making use of the opportunity to connect with the luxury buyer. In the fashion and automobile sectors, the majority of luxury 
firms do offer customization where buyers are involved in the design of the product. In contrast, the customization feature is low in watches, jewelry and yachts. Very few brands across the five luxury sectors offer personalization, where buyers can add their initials or personal mark. The use of a sign-in feature, thus enabling brands to recognize visitors who are logged in, is particularly evident in the fashion sector but the use of this feature is low in the other 4 sectors.

Tables 4 - 7 present the findings from a one-way analysis of variance (ANOVA). Statistically significant differences across the different luxury sectors are highlighted

$$
\begin{aligned}
& \longleftrightarrow<<<\text { Insert Table } 3 \text { Here } \quad \gg>>> \\
& \langle<<<\text { Insert Table } 4 \text { Here } \quad \gg>>>
\end{aligned}
$$

ANOVA results in Table 4 demonstrate that there are statistically significant differences in the way the various luxury sectors use the $8 \mathrm{C}$ characteristics online. Leven's test for homogeneity of variances was significant for several of our categories at the 0.05 level, suggesting that the population variances for each group are not approximately equal. To further investigate, we used the Welsh test of equality of means. This test showed there were significant differences across luxury sectors in four of the eight categories: content, collaboration, commerce, and customization (see highlighted results in Table 4). Having obtained significant results for these categories, we then determined, using a Games-Howell test, where significant differences existed. With regard to content, the Games-Howell test indicated that the jewelry sector has a significantly higher mean score for content relative to the yachts sector. Inspection of Table 5 indicates the low use of content-related characteristics in the yacht sector. Yachts have the lowest mean, with the others sectors more similar. With regard to collaboration, again yachts stand out as making less use of this website characteristic than other sectors, as indicated in Table 5. Yachts have the lowest mean score for collaboration. The Games-Howell test indicated that the watches sector had a 
significantly higher mean score for collaboration relative to the yachts sector. For commerce, the fashion sector had a significantly higher mean score relative to all other sectors. Means, in descending order, begin with fashion, followed by jewelry, watches, autos, and then no use whatsoever of commerce-related website characteristics in yachts. The Games-Howell test also indicated that the jewelry sector had a significantly higher mean score for commerce relative to the yachts sector. Finally, statistically significant results on customization are tied to the lower mean of the watches sector relative to autos, fashion, and yachts. Specifically, the yachts sector had a significantly higher mean score for customization relative to autos, jewelry and watches. The fashion sector also had a significantly higher mean score for customization relative to the watches sector.

\section{$\ll<<<\quad$ Insert Table 5 Here $\quad \gg>>>$}

ANOVA results also demonstrate significant differences in how different sectors use the Internet for branding, selling, one-way communication, two-way communication, and operational features (see Table 6). For branding-related characteristics, the Games-Howell test revealed that jewelry had a significantly higher mean scores relative to the fashion and yacht sectors. The watches sector also had a significantly higher mean score for brand-related characteristics relative to the fashion and yacht sectors. Table 7 further reveals the lowest adoption of this characteristic in the yachts sector. For selling, the fashion sector had a significantly higher mean score than the watches sector. Statistically significant results for one-way communication appear to be driven by high means for autos, watches, and jewelry, with a low value for yachts. The Games-Howell test revealed that autos and watches sectors had a significantly higher mean score for one-way communication relative to the yachts sector. In terms of two-way communication, the fashion sector had a significantly higher mean score than both the autos and watches sectors. Operational 
website characteristics are widely used in all sectors except yachts. The Games-Howell test also revealed that the fashion and jewelry sectors had a significantly higher mean score than yachts.

In summary, our findings shown in Tables 4-7 highlight similarities and differences in the way different luxury sectors have embraced digital technologies in their websites. There were significant differences across luxury sectors in content, collaboration, commerce, and customization. The website characteristics of branding, selling, one-way communication, two-way communication, and the use operational features also differed across luxury sector.

$$
\begin{aligned}
& \ll<<<\text { Insert Table } 6 \text { Here } \quad \gg>>>> \\
& <<<<\quad \text { Insert Table } 7 \text { Here } \quad \gg>>>
\end{aligned}
$$

\section{Discussion}

Having observed differences across sectors in terms of how each of the $8 \mathrm{C}$ website elements are used, we now proceed to offer explanation for our findings, and to describe their implications. In doing so, we draw upon existing theory and literature to explain why luxury firms use particular website features and characteristics.

\subsection{Theoretical Implications}

As firms consider whether they will engage only in branding online, or if they will also engage in selling, several considerations come to light. One potential explanation for differences across sectors is the variation in product complexity. Product complexity is defined as the amount of information needed to specify the attributes of a product in enough detail to allow potential buyers to make a selection (Malone et al., 1987). Product complexity is a function of the number of components and their technological intensity (Lamming et al., 2000). Watches and yachts exhibit high complexity whereas fashion exhibits relatively low complexity, perhaps indicating a distinction in how such products will be presented to consumers online. Indeed, our results indicate that less-complex products are more likely to be sold online (high usage of commerce- 
related features), whereas complex products are unlikely to be sold online (low usage of commerce-related features). Complexity would appear to be something that augurs for an in-store, hands-on, or associate-guided demonstration.

Luxury sectors also differ in terms of product fashionableness (Caniato et al., 2009). Sectors high in fashionableness include those that have aesthetic requirements that vary over time. Fashion items such as apparel, shoes, bags, and accessories, for example, are typically subject to seasonal fashion trends. Yachts are extremely durable, long-lasting, and are much less fashion-sensitive, again indicating a potential difference in how such products will be marketed. Indeed, our results indicate that fashion is the most likely of all sectors to sell online.

Sales volume has been highlighted as an important factor in supply chain management considerations for luxury firms (Caniato et al., 2011). We observe that this factor also has relevance for firms that are considering whether they will only engage in branding online or branding as well as selling. For firms in sectors that can enjoy a relatively high sales volume, the ability to automate transactions by moving them online is a strong rationale for building an ecommerce site. Fashion, for instance, with its high level of transactions would benefit from ecommerce sites where selling takes place online, while yachting firms, with extremely low sales volumes would not generally consider selling online. The differences across sectors in the mean usage of the Internet for branding and selling appear in figure 1 below.

\section{$\ll<<\quad$ Insert Figure 1 Here $\quad>>>>$}

As firms consider the use of one-way and two-way communications, several additional considerations come to light. Researchers argue that depending on fashion sensitiveness, a luxury product can be considered a symbolic luxury or a technical luxury (Brun et al., 2008; Brun and Castelli, 2008). That is, some products are primarily recognized for their technical features 
whereas others, in the eyes of the customer, are primarily symbolic. For example, people buy Ferrari because of the vehicles' world-class performance and engineering, while other luxury brands such as Gucci, are valued more for the lifestyle they project than for the particular capability or functionality they embody. While our results show a high level of one-way communication by all types of luxury brands, our results show the greatest amount of product information and oneway communication provided by firms in the automobile sector, which we suggest indicates a desire to thoroughly communicate the aspects of technical luxury to consumers.

While consumers of products that are more technical in nature would seem to prefer more detailed product information and excellent service, fashion-related products, which are more of a symbolic luxury, might be better suited to socially-rich website characteristics that provide a degree of interactivity with the brand (Burke, 2002). Instilling a sense of human warmth and socialibility in this sector is clearly important and this is accomplished by providing the means for actual with the brand as well as socially rich text and visual content in the form of audio and video. Clearly, two-way communication features are much less widely-used than one-way communication across all sectors, fashion. Nevertheless, fashion, which seems best-suited to benefit from high levels of interactivity and social presence, leads the way on this characteristic. This finding supports the work of Hassanein and Head (2005) who found that clothing and apparel are better suited for socially-rich website design. Including a sense of social presence may be less appropriate for the other luxury sectors because they do not match the experiential requirements for online customers seeking such products. Our data shows that the sector with firms that are most active on social media and use social media to allow customers express their opinion and write about their experiences with the brand is fashion. 
Additionally, we observe that products where assistance and product contact may be required will lend themselves to two-way communication. Fashion, for instance, where items are generally tried on during an in-store experience, seems more likely to use two-way communication than products that do not need such interaction and experience. Michael Kors, for instance, is currently experimenting with a virtual try-on feature that uses a consumer's smartphone camera and the Snapchat app to show how an item will look when worn (Luxury Daily, 2016). Indeed, our results show that fashion is the most likely sector to engage in two-way communication.

\section{$<<<<\quad$ Insert Figure 2 Here $\quad \gg>>>$}

Finally, as firms consider whether to use their website for strictly operational functions or also for innovative functions, we again note the importance of sales volume. For firms with higher sales volume, the provision of operational features through the website appears to more highlyvalued. This is particularly evident in the fashion sector. Yachts, with their much lower sales volume lag the other sectors noticeably. Differences across sectors are illustrated in Figure 3. Interestingly, no significant differences were observed when comparing the category of innovation across luxury sector. However, closer inspection of specific innovation features such as augmented reality and product customization highlight some interesting observations. For example, the use of product customization is more prevalent in the autos and fashion sectors. Autos are easily customizable because products are made through the assembly of discreet parts. Customizations are more common for products that can be modularized relatively easily and product attributes in this sector are primarily utilitarian and quantifiable. The benefits of online customization are also recognized in the fashion and apparel sectors (Okonkwo, 2010) where customers seek ways to enhance self-expression. However, innovative features that permit 
personalization and the use of augmented reality to improve product presentation and encourage customer acquisition, is low across all sectors (Jaekel, 2016).

$<<<<\quad$ Insert Figure 3 Here $\quad \gg>>>$

\subsection{Practical Implications}

Comparing our results with those of an earlier research study on the 8C framework (BjørnAndersen and Hansen, 2011) reveals increasing use of the content, connection, commerce, context, and customization, at least within the luxury fashion sector. We observe that most of these website elements are related to selling. This continues a trend towards online selling that has been observed for the past decade. As luxury brands continue to move towards more online retailing, there are several key considerations they should take into account.

First, firms can explore ways to replicate the product and the experience of it in the online environment. For instance, the adoption of animation, augmented reality, and 360 degree view is low across sectors. This is even true in the fashion sector, with its products that would generally seem to require a higher degree of assistance and product contact than other sectors. Furthermore, although product customization and personalization lie at the heart of luxury (Kapferer and Bastien, 2012), it is evident from our results that some luxury sectors are not making use of this opportunity to connect with the luxury buyer with a customized product or customized experience. Our findings are consistent with those reported in industry publications, indicating that only 23 percent of luxury retailers are incorporating digital personalization tools into their online presence (Jaekel, 2016). If luxury brands can enable interaction with the product using advanced technologies, can also identify ways to replicate the sales associate interaction online, and also provide individualized and customized offerings, they will be well-prepared to create the premium, luxurious, exclusive, high-touch interaction that luxury consumers desire. 
Second, luxury firms are encouraged to embrace the move towards omnichannel marketing that has been witnessed in mass market firms. Customers may desire to experience a product instore, but then purchase online. They may also want to research a product online before buying in-store. Rather than resisting this trend, luxury brands should embrace the opportunity to open a new marketing and sales channel online, one that complements their existing, premium in-store experience.

The Internet dilemma of selling online is addressed against the backdrop of trust in electronic commerce. In some regions, a high degree of trust exists and electronic commerce is welldeveloped, while in other regions there is a low degree of trust in online websites, electronic payment systems, and delivery methods. Luxury firms can take advantage of the lack of trust in some markets where e-commerce is nascent by taking a leadership position and demonstrating themselves to be reputable, trustworthy, and reliable online merchants. They have the slack resources and profit margins to invest in the order fulfillment and delivery process, personalizing and customizing the moment of delivery in order to build trust and enhance the brand. They fact that luxury firms can offer a reliable, secure online experience is a premium service that other retailers may not yet offer.

Fourth, in spite of the challenges of the Internet dilemma, luxury brands should carefully consider the value of the data that can be gleaned from consumers through the online website. Product searches, clickstreams, virtual-try-ons, tweets, photos, community membership, and a host of other features provide a wealth of information about consumers. While there is admittedly a school of thought that luxury brands do not do market research and produce what they see as beautiful and artistic (Kapferer and Bastien, 2012), they ignore market conditions and the 
consumer base at their own peril. Failed firms may have been true to their ethos, but pyrrhic victories may matter little to luxury firms' former employees, shareholders, and customers.

As a final note, luxury firms should make their online strategy in light of the product characteristics that we noted in section 5.1. Sales volumes, fashionableness, product complexity, the question of technical or symbolic luxury, and the need for product assistance each dictate a unique strategic approach to the Internet dilemma.

\subsection{Limitations and Future Research}

We acknowledge the limitations associated with the exploratory nature of our research. The research undertaken is in a field where literature remains lacking. The purpose of the current study is therefore to shed light on the ways in which luxury firms are addressing the Internet Dilemma rather than attemping to explain it with cause-effect relationships. We argue that identifying the strategic choices of luxury brands (website purpose, mode of interaction, and level of interaction) constitues a first step in better understanding how luxury brands are embracing Internet-based technologies.

We also note that additional research methods, additional sectors, and additional product characteristics would enrich and extend the findings presented here. Only qualitative content analysis was used in the present study; other evaluation methods including online surveys and experiments warrant consideration in future research to examine customer attitudes towards luxury firm website characteristics. We also note that luxury brand websites are in constant flux. Our results are therefore time-constrained. Future research, possibly with different methods, should reproduce this study in order to achieve a longitudinal perspective of the results. With regard to additional sectors, hospitality, fragrances, and furnishings are among the possibilities for future investigation. Furthermore, as other sectors are considered, there are potentially other product 
characteristics such as search and experience attributes that could be used to differentiate luxury products. An understanding of such attributes may also help explain differences in the adoption of Internet-based technologies by luxury firms in their websites.

\section{Conclusion}

In this paper, we began by making the observation that the Internet strategy of luxury firms is under-investigated. Preserving the luxury brand's image of exclusiveness and uniqueness within the Internet mass medium represents a fundamental challenge for luxury firms. Building from this observation, we have looked at how these firms can use the Internet strategically in their marketing, retailing, and customer service functions. This objective was reached by the content analysis of 92 luxury brand websites across 5 different luxury sectors. Our review of the extant literature has highlighted the possibilities of digital technologies for luxury brands with branding, online selling, two-way communication and innovative uses of the Internet to promote and customize products as the key activities. Our results possessed good inter-rater consistency and showed that not all of these activities are being fully exploited by luxury brands. Our ideas link different website characteristics to product attributes. We provide insight into how luxury firms can use IT to accomplish their strategic marketing (and sometimes retailing) objectives. We believe that a systematic approach to the use of Internet technologies in luxury firms, should yield improvements in brand equity, customer satisfaction, and organizational performance. We look forward to future research that continues to examine these issues. 


\section{References}

Atwal, G., Williams, A. (2009) Luxury brand marketing-the experience is everything! Journal of Brand Management 16, 338-346.

Barbosa, M., Motta, J., Brandão, N., Filipe, S. (2013) Os new media como instrumento de comunicação política: estudo do caso das eleições legislativas em 2011 na península ibérica.

Berger, R. (2012). Chinese consumers report-Luxury; A brand awareness upgrade. Welcoming a new era in the Chinese luxury market.

Berthon, P., Pitt, L., Parent, M., Berthon, J.-P. (2009) Aesthetics and ephemerality: observing and preserving the luxury brand. California management review 52, 45-66.

Bjørn-Andersen, N., Hansen, R. (2011). The adoption of Web 2.0 by luxury fashion brands, KMIS \& Conf-IRM International Conference 2011: Service Management and Innovation with Information technology.

Brun, A., Caniato, F., Caridi, M., Castelli, C., Miragliotta, G., Ronchi, S., Sianesi, A., Spina, G. (2008) Logistics and supply chain management in luxury fashion retail: Empirical investigation of Italian firms. International Journal of Production Economics 114, 554-570.

Brun, A., Castelli, C. (2008) Supply chain strategy in the fashion industry: developing a portfolio model depending on product, retail channel and brand. International Journal of Production Economics 116, 169-181.

Brun, A., Liu, X., Burns, A.C., Hou, Y. (2013) Comparing online and in-store shopping behavior towards luxury goods. International Journal of Retail \& Distribution Management 41, 885-900.

Bryman, A. (2008) Why do researchers integrate/combine/mesh/blend/mix/merge/fuse quantitative and qualitative research. Advances in mixed methods research, 87-100.

Burke, R. (2002) Hybrid recommender systems: Survey and experiments. User modeling and useradapted interaction 12, 331-370.

Caniato, F., Caridi, M., Castelli, C., Golini, R. (2011) Supply chain management in the luxury industry: a first classification of companies and their strategies. International Journal of Production Economics 133, 622-633.

Caniato, F., Caridi, M., Castelli, C.M., Golini, R. (2009) A contingency approach for SC strategy in the Italian luxury industry: do consolidated models fit? International Journal of Production Economics 120, 176-189.

Cohen, J. (1968) Weighted kappa: Nominal scale agreement provision for scaled disagreement or partial credit. Psychological bulletin 70, 213.

Constantinides, E., Fountain, S.J. (2008) Web 2.0: Conceptual foundations and marketing issues. Journal of direct, data and digital marketing practice 9, 231-244.

Coursaris, C., Hassanein, K., Head, M. (2006). Mobile Technologies and the Value Chain: Participants, activities and value creation, Mobile Business, 2006. ICMB'06. International Conference on. IEEE, pp. 8-8.

D'Arpizio, C. (2013). Luxury Goods Worldwide Market Study Fall 2013, Bain \& Company.

Daft, R.L., Lengel, R.H. (1986) Organizational information requirements, media richness and structural design. Management science 32, 554-571.

Dall'Olmo Riley, F., Lacroix, C. (2003) Luxury branding on the Internet: lost opportunity or impossibility? Marketing Intelligence \& Planning 21, 96-104.

David, S. (2005) Doing qualitative research. Los Angeles: Sage Transparency International (2009), Corruption perception index, retrieved on 20, 2010. 
De Barnier, V., Falcy, S., Valette-Florence, P. (2012) Do consumers perceive three levels of luxury\&quest; A comparison of accessible, intermediate and inaccessible luxury brands. Journal of Brand Management 19, 623-636.

Fulk, J., Steinfield, C.W., Schmitz, J., Power, J.G. (1987) A social information processing model of media use in organizations. Communication research 14, 529-552.

Geerts, A. (2013) Cluster analysis of luxury brands on the internet. International Journal of Management and Marketing Research 6, 79-82.

Geerts, A., Veg-Sala, N. (2011) Evidence on internet communication management strategies for luxury brands. Global Journal of Business Research 5, 81-94.

Hansen, R., Bjorn-Andersen, N. (2013) Cube assessment framework for B2C websites applied in a longitudinal study in the luxury fashion industry. Journal of theoretical and applied electronic commerce research 8, 1-20.

Hassanein, K., Head, M. (2005) The impact of infusing social presence in the web interface: An investigation across product types. International Journal of Electronic Commerce 10, 31-55.

Hennigs, N., Wiedmann, K.P., Klarmann, C., Strehlau, S., Godey, B., Pederzoli, D., Neulinger, A., Dave, K., Aiello, G., Donvito, R. (2012) What is the Value of Luxury? A Cross-Cultural Consumer Perspective. Psychology \& Marketing 29, 1018-1034.

Jaekel, B. (2016) Luxury Industry is Severely Missing Personalization in Online Experience. Luxury Daily Nov 28.

Kapferer, J.-N., Bastien, V. (2012) The Luxury Strategy: Break the Rules of Marketing to Build Luxury Brands. Kogan Page Publishers.

Keller, K.L. (2008) Strategic Brand Management, International Edition: Best Practice Cases in Branding. Pearson Education.

Keller, K.L. (2010) Brand equity management in a multichannel, multimedia retail environment. Journal of Interactive Marketing 24, 58-70.

Kiang, M.Y., Raghu, T., Shang, K.H.-M. (2000) Marketing on the Internet-who can benefit from an online marketing approach? Decision Support Systems 27, 383-393.

Kim, A.J., Ko, E. (2012) Do social media marketing activities enhance customer equity? An empirical study of luxury fashion brand. Journal of Business Research 65, 1480-1486.

Kluge, P.N., Fassnacht, M. (2015) Selling luxury goods online: effects of online accessibility and price display. International Journal of Retail \& Distribution Management 43, 1065-1082.

Kluge, P.N., Königsfeld, J.A., Fassnacht, M., Mitschke, F. (2013) Luxury web atmospherics: an examination of homepage design. International Journal of Retail \& Distribution Management 41, 6-6.

Krippendorf, K. (1980) Quantitative content analysis: An introduction to its method. Beverly Hill: Sage publications.

Lamming, R., Johnsen, T., Zheng, J., Harland, C. (2000) An initial classification of supply networks. International Journal of Operations \& Production Management 20, 675-691.

Landis, J.R., Koch, G.G. (1977) The measurement of observer agreement for categorical data. biometrics, 159-174.

Lee, Y.E., Benbasat, I. (2004) A framework for the study of customer interface design for mobile commerce. International Journal of Electronic Commerce 8, 79-102.

Liu, Y., Shrum, L.J. (2002) What is Interactivity and is it Always Such a Good Thing? Implications of Definition, Person, and Situation for the Influence of Interactivity on Advertising Effectiveness. Journal of Advertising 31, 53-64. 
Luxury Daily. (2016). Michael Kors creates virtual sunglass trial using Snapchat lens. https://www.luxurydaily.com/michael-kors-creates-virtual-sunglass-trail-using-snapchatlens/, Luxury Daily, June 27, 2016.

Mahyari, P. (2013). Luxury Brand Identity: The Influence of Mobile Digital Technology. Unpublished Doctor of Philosophy Thesis, Queenland University of Technology.

Malone, T.W., Yates, J., Benjamin, R.I. (1987) Electronic markets and electronic hierarchies. Communications of the ACM 30, 484-497.

Nyeck, S. (2004) Luxury brands online and offline: the case of French brands. European Retail Digest, 20-24.

Okonkwo, U. (2009) Sustaining the luxury brand on the Internet. Journal of Brand Management $16,302-310$.

Okonkwo, U. (2010) Luxury online: Styles, systems, strategies. Palgrave Macmillan.

Phan, M., Thomas, R., Heine, K. (2011) Social media and luxury brand management: The case of Burberry. Journal of Global Fashion Marketing 2, 213-222.

Rayport, J.F., Jaworski, B.J. (2001) Cases in e-Commerce. McGraw-Hill Higher Education.

Riley, F.D.O., Lacroix, C. (2003) Luxury branding on the Internet: lost opportunity or impossibility? Marketing Intelligence \& Planning 21, 96-104.

Sabouri, M., Jalali, A.A. (2009). Evaluating web 2.0 services based on 7C framework, 2009 Sixth International Conference on Information Technology: New Generations. IEEE, pp. 1693-1694.

Seringhaus, F.R. (2005) Selling luxury brands online. Journal of Internet Commerce 4, 1-25.

Siddiqui, N., O'Malley, A., McColl, J.C., Birtwistle, G. (2003) Retailer and consumer perceptions of online fashion retailers: Web site design issues. Journal of Fashion Marketing and Management: An International Journal 7, 345-355.

Tynan, C., McKechnie, S., Chhuon, C. (2010) Co-creating value for luxury brands. Journal of Business Research 63, 1156-1163.

Vigneron, F., Johnson, L.W. (2004) Measuring perceptions of brand luxury. The Journal of Brand Management 11, 484-506.

Wiedmann, K.-P., Hennigs, N. (2013) Luxury marketing. A challenge for theory and.

Yang, T.A., Kim, D.J., Dhalwani, V., Vu, T.K. (2008). The 8C framework as a reference model for collaborative value Webs in the context of Web 2.0, Hawaii International Conference on System Sciences, Proceedings of the 41st Annual. IEEE, pp. 319-319.

Yoo, B., Donthu, N., Lee, S. (2000) An examination of selected marketing mix elements and brand equity. Journal of the academy of marketing science 28, 195-211. 